\title{
Experimental power and thrust coefficients of a shrouded horizontal axis hydrokinetic turbine in yaw operation
}

\author{
Authors: \\ Mohammad Shahsavarifard, Eric Louis Bibeau \\ Department of Mechanical Engineering, University of Manitoba
}

\begin{abstract}
Dataset includes power and thrust coefficients of a $19.8 \mathrm{~cm}$ diameter horizontal axis hydrokinetic model turbine in yaw operation. Tests were done at $0.7,0.9$, and $1.1 \mathrm{~m} / \mathrm{s}$ water speeds for three turbine configurations: the unshrouded turbine and the turbine with two different shrouds. Experiments were done for yaw angles from $5^{\circ}$ to $25^{\circ}$ in $5^{\circ}$ intervals. Output power of the turbine and its thrust force are measured experimentally in a water tunnel. Results are corrected using a theoretical model that accounts for free surface proximity and blockage effects of the water tunnel.
\end{abstract}

Keywords: Hydrokinetic turbine, shroud, yaw misalignment, performance, thrust coefficient 


\section{$1 \quad$ Water tunnel}

Tests are carried out in the recirculating water tunnel facility at the University of Manitoba. The tunnel has a $61 \mathrm{~cm}$ wide by $183 \mathrm{~cm}$ long test section and allows maximum of $60 \mathrm{~cm}$ water height. A propeller pump provides water flow up to $1.1 \mathrm{~m} / \mathrm{s}$ velocity at the test section for the full water height. Turbulence intensity of the flow at the test section is less than $3 \%$ for the maximum speed.

\section{The model turbine}

The model turbine has a rotor blade and allows use of shrouds. The rotor blade is a $19.8 \mathrm{~cm}$ diameter three bladed H0127 wind turbine blade of KidWind Project Inc. with a solidity of 0.13. Two shrouds are designed, manufactured, and used in the experiments. One is a duct of convergent-divergent profile referred to as the shroud. The other is a straight wall duct referred to as the diffuser. Schematics of profile and photos of the shroud and the diffuser are depicted in Figure 1 and the geometric characteristics are summarized in Table 1. Thickness of the diffuser wall is $9 \mathrm{~mm}$. 

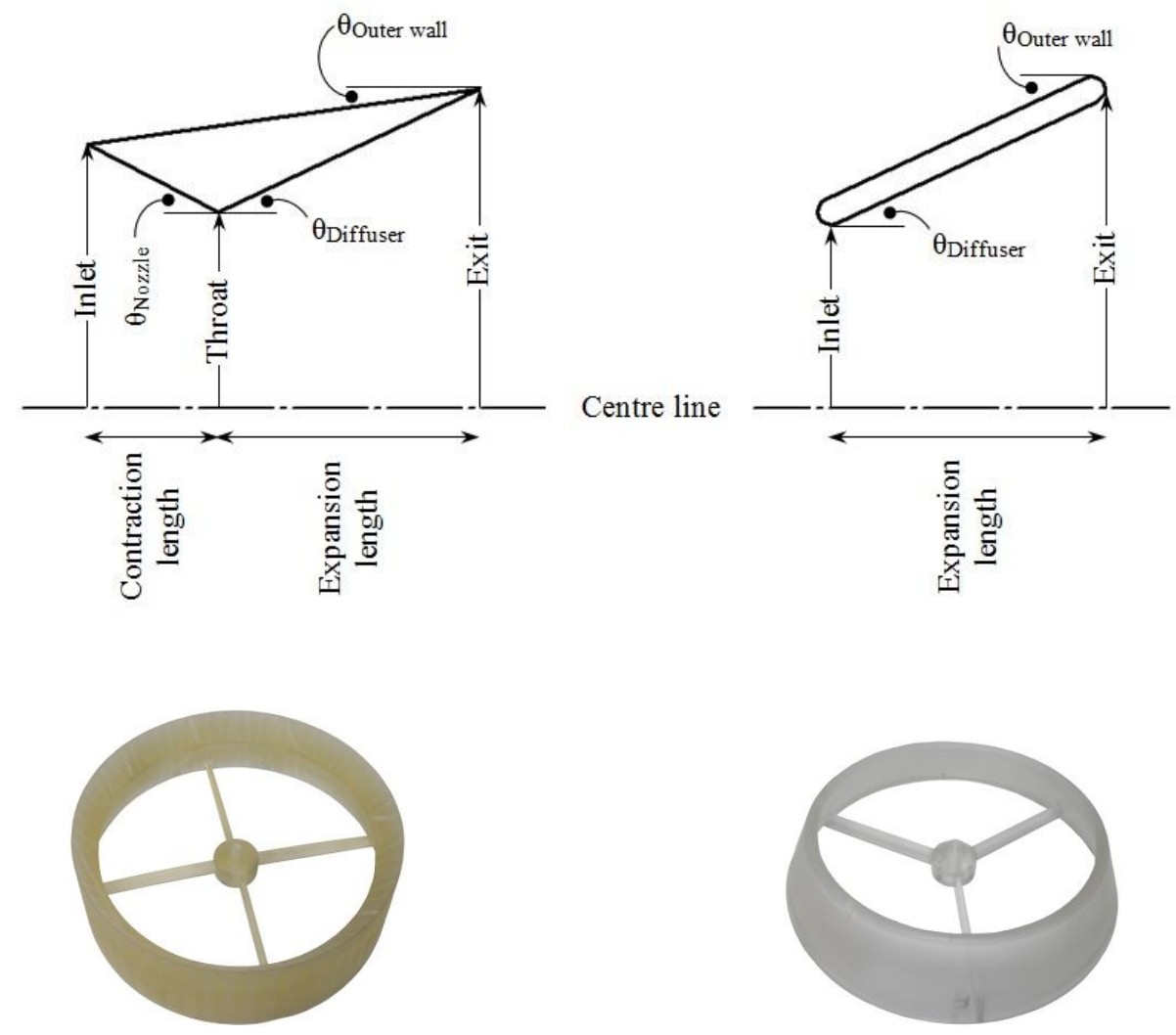

Figure 1: Schematic profile and photo of the shroud (left) and the diffuser (right)

Table 1: Dimensions of the shroud and the diffuser

\begin{tabular}{lcc}
\hline Dimension & Shroud & Diffuser \\
\hline Inlet diameter $(\mathrm{cm})$ & 22.6 & 20.1 \\
Throat diameter $(\mathrm{cm})$ & 20.1 & --- \\
Exit diameter $(\mathrm{cm})$ & 25.0 & 25.0 \\
Contraction length $(\mathrm{cm})$ & 2.5 & --- \\
Expansion length $(\mathrm{cm})$ & 5.2 & 5.2 \\
Nozzle half angle $\left({ }^{\circ}\right)$ & 27 & --- \\
Diffuser half angle $\left(^{\circ}\right)$ & 25 & 25 \\
Outer wall angle $\left(^{\circ}\right)$ & 8 & 25 \\
\hline
\end{tabular}




\section{Dataset}

The dataset contains experimental values of power and trust coefficients for the shrouded and unshrouded turbines for yaw angles from $5^{\circ}$ to $25^{\circ}$. The first column in each cluster of data is TSR and the second column is the coefficients. Tip speed ratio, power and trust coefficients are calculated as follows:

$$
\begin{gathered}
T S R=\frac{R \omega}{V} \\
C_{P}=\frac{Q \omega}{1 / 2 \rho A V^{3}} \\
C_{T}=\frac{T}{1 / 2 \rho A V^{2}}
\end{gathered}
$$

where $\mathrm{Q}$ and $\mathrm{T}$ are torque and thrust of the turbine and $\omega$ and $\mathrm{V}$ are respectively the angular velocity of the turbine shaft and the flow speed. The power and thrust coefficients are calculated based on the swept area of the rotor blade, A. 